\title{
于淑会团队设计具有等电子阱的纳米粒子作为填料 提高聚合物复合材料的电击穿强度
}

中国科学院深圳先进技术研究院先进电子材 料研究中心于淑会与孙蓉团队在提高聚合物复合 材料的击穿强度和静电能量密度研究取得进展。 相应成果 “Nanoparticles with rationally designed isoelectronic traps as fillers significantly enhance breakdown strength and electrostatic energy density of polymer composites (通过合理设计具有等电子 阱的纳米粒子作为填料提高聚合物复合材料的击 穿强度和静电能量密度)”于 2020 年 7 月 28 日 发表在 Composites Science and Technology 上。

电气和电子系统小型化的发展进程, 迫切需 要研发具有高能量密度和高充放电效率的电介质 聚合物纳米复合材料。提高复合材料能量密度的 一个关键挑战是抑制复合材料中载流子的运动, 这直接关系到材料的电击穿强度以及充放电效 率。因此, 通过对填料的理化性质进行合理的设 计, 使其具备束缚载流子运动的能力, 将有效提 高复合材料的放电能量密度及充放电效率, 使得 聚合物复合薄膜在电子电力系统小型化发进程中 发挥作用。

该研究利用固相反应法将 $\mathrm{ZnS}$ (硫化锌) 中的 一部分 $\mathrm{S}$ 元素用 $\mathrm{O}$ 元素取代制备了 $\mathrm{ZnS}: \mathrm{O}$ 纳米 颗粒。由于 $S$ 元素和 $O$ 元素之间的电负性差异 $(\Delta \mathrm{EN}=0.86)$, 在 $\mathrm{ZnS}: \mathrm{O}$ 纳米颗粒中形成等电子 陷阱, 可以在一定程度上束缚空间电荷, 并抑制 空间电荷的移动。以 $\mathrm{ZnS}: \mathrm{O}$ 纳米颗粒为填料, 采 用二次分散法将其引入到聚偏氟乙烯 (PVDF) 基 体中制备了 $\mathrm{ZnS}: \mathrm{O} / \mathrm{PVDF}$ 复合薄膜。

结果显示, $\mathrm{ZnS}: \mathrm{O} / \mathrm{PVDF}$ 复合材料的击穿强度 $E_{\mathrm{b}}$ 高达 $6000 \mathrm{kV} / \mathrm{cm}$, 能量密度可达 $14.4 \mathrm{~J} / \mathrm{cm}^{3}$, 分别是纯 $\operatorname{PVDF}\left(E_{\mathrm{b}} \sim 3183 \mathrm{kV} / \mathrm{cm}, 4.6 \mathrm{~J} / \mathrm{cm}^{3}\right)$ 的 2 倍和 3 倍以上, 并且高于以 $\mathrm{ZnS}$ 为填料的 PVDF 基
复合材料。此外, 等电子陷阱结构的引入也使得 ZnS:O/PVDF 复合材料的充放电效率高达 97\%。

该研究以设计具有特定物理特性的纳米颗粒 为出发点, 首次从等电子陷阱的角度提升复合材 料的电击穿强度, 突破了常规填料结构设计的局 限。从电击穿及损耗的产生机理入手，通过人为 引入势阱来抑制载流子的运动, 从根本上提升复 合材料的击穿强度和放电能密度, 并降低介电损 耗。这为复合介电材料的发展提供了新的研究思 路, 为电子、电力系统的集成化和小型化发展提 供了更多的可能。
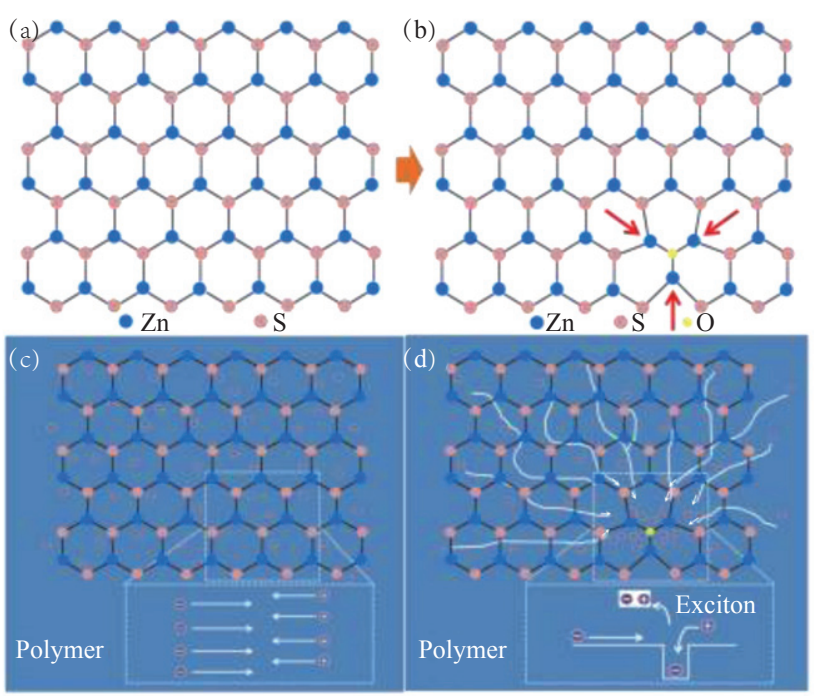

(a) $\mathrm{ZnS}$ 的 (111) 面; (b) $\mathrm{ZnS:O}$ 的 (111) 面; (c) $\mathrm{ZnS} / \mathrm{PVDF}$ 复合薄膜中电子与空穴的运动; (d) $\mathrm{ZnS}: \mathrm{O}$ 晶格中激子的形 成过程

晶格中的空间电荷移动示意图 ${ }^{[1]}$

[1] Yu JY, Ding SJ, Yu SH, et al. Nanoparticles with rationally designed isoelectronic traps as fillers significantly enhance breakdown strength and electrostatic energy density of polymer [J]. Composites Science and Technology, 2020, 195: 108201. 